\title{
Adsorptive removal of arsenic from aqueous solution by zeolitic imidazolate framework-8 (ZIF-8) nanoparticles
}

\author{
Meipeng Jian ${ }^{\mathrm{a}}$, Bao Liu ${ }^{\mathrm{a}}$, Gaosheng Zhang ${ }^{\mathrm{b}}$, Ruiping Liu ${ }^{\mathrm{a}, *}$, Xiwang Zhang ${ }^{\mathrm{c}, * *}$ \\ a Key Laboratory of Drinking Water Science and Technology, Research Center for Eco-Environmental Sciences, Chinese Academy of Sciences (CAS), \\ Beijing 100085, China \\ ${ }^{\mathrm{b}}$ Key Laboratory of Coastal Zone Environmental Processes, Yantai Institute of Coastal Zone Research (YIC), Chinese Academy of Sciences (CAS), \\ Yantai, Shandong 264003, China \\ ' Department of Chemical Engineering, Monash University, Clayton, Victoria 3800, Australia
}

\section{H I G H L I G H T S}

- ZIF-8 nanoparticles have been fabricated via a facile method at room temperature.

- The ZIF-8 nanoparticles show high adsorption capacity for arsenic removal at neutral and basic conditions.

- Electrostatic attraction and hydroxyl and amine groups play key roles in the adsorption process.

\section{A R T I C L E I N F O}

\section{Article history:}

Received 2 July 2014

Received in revised form

28 September 2014

Accepted 6 October 2014

Available online 18 October 2014

\section{Keywords:}

Zeolitic imidazolate framework-8

Arsenic

Adsorption

Zeta potential

Mechanisms

\section{G R A P H I C A L A B S T R A C T}

(a)
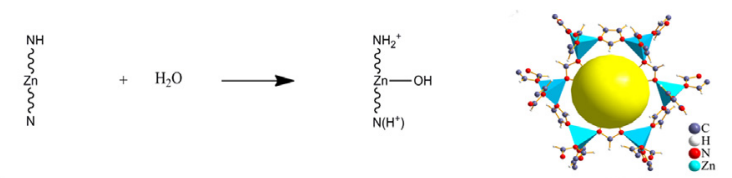

(b)
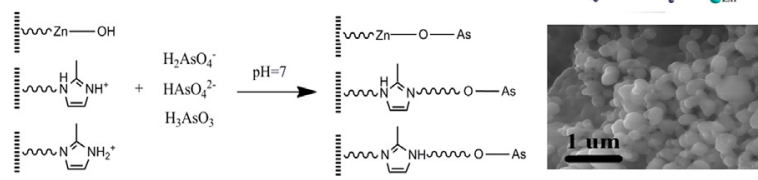

\begin{abstract}
A B S T R A C T
In this study, zeolitic imidazolate framework-8 (ZIF-8) nanosorbent was successfully synthesized via a facile method at room temperature. The ZIF-8 nanoparticles were characterized by nitrogen sorption, powder X-ray diffraction, field emission scanning electron microscope, transmission electron microscopy and Zeta potential. The synthesized ZIF-8 nanoparticles exhibited a high surface area of $1063.5 \mathrm{~m}^{2} / \mathrm{g}$ and were of $200-400 \mathrm{~nm}$ in particle size. The kinetic and isotherm data of arsenic adsorption on ZIF- 8 were well fitted by pseudo-second-order and Langmuir models, respectively. The maximal adsorption capacities of $\mathrm{As}(\mathrm{III})$ and $\mathrm{As}(\mathrm{V})$ were of 49.49 and $60.03 \mathrm{mg} / \mathrm{g}$, respectively, at $T=25^{\circ} \mathrm{C}$ and $\mathrm{pH}$ 7.0. The ZIP-8 nanoparticles were stable at neutral and basic conditions. However, large amounts of $\mathrm{Zn}^{2+}$ were released into water from the sorbent at acidic condition, which dramatically hindered the adsorption of arsenic. $\mathrm{SO}_{4}{ }^{2-}$ and $\mathrm{NO}_{3}{ }^{-}$had no significant effect on the arsenic adsorption while the adsorption was significantly inhibited by $\mathrm{PO}_{4}{ }^{3-}$ and $\mathrm{CO}_{3}{ }^{2-}$. X-ray photoelectron spectroscopy and Fourier transform infrared spectroscopy analysis revealed that electrostatic attraction and hydroxyl and amine groups on ZIF-8 surface played vital roles in the adsorption process.
\end{abstract}

(c) 2014 Elsevier B.V. All rights reserved.

\footnotetext{
* Corresponding author. Tel.: +86 01062849160 .

** Corresponding author. Tel.: +61 399051867.

E-mail addresses: liuruiping@rcees.ac.cn (R. Liu), xiwang.zhang@monash.edu (X. Zhang).
}

\section{Introduction}

Arsenic contamination in natural waters causes a worldwide environmental concern since arsenic-polluted water could lead to great risk to human health due to its high toxicity. Many countries have been suffering from serious arsenic pollution, such as China, Japan, Bangladesh, India, etc. [1]. The maximum contaminant level $(\mathrm{MCL})$ of arsenic in drinking water was recommended by the World 
Health Organization (WHO) to be of $10 \mu \mathrm{g} / \mathrm{L}$ in 2006 [2]. As a result of this new guideline, the development of innovative technologies and processes for arsenic removal from wastewater is of critical importance. So far, various techniques, such as chemical precipitation, coagulation, reverse osmosis, membrane, and ion exchange, have been studied for arsenic removal. However, these technologies are usually high costly, complex, and low efficient [3]. Thus, there is an urgent demand for an economical, effective, and reliable technique for arsenic removal. Adsorption is considered to be one of the most promising approaches due to low cost, easy maintenance and high efficiency [2]. Various types of sorbents have been reported in arsenic removal; however, the adsorption capacity of conventional sorbents is generally limited by their chemical properties and irregular pore structures [4].

Metal organic frameworks (MOFs), also known as porous coordination polymers, are a novel class of highly porous materials, which have received increasing attention in the last decade due to their unique properties, such as ultrahigh surface area (up to $7000 \mathrm{~m}^{2} / \mathrm{g}$ ), tunable pore structures, high crystallinity and designable organic ligands $[5,6]$. In particular, zeolitic imidazolate frameworks (ZIFs) are a subclass of metal organic frameworks with zeolite or zeolitelike topologies, which possess several extraordinary features, such as chemical robustness and thermal stability [7,8]. Among various ZIFs materials, ZIF-8 which is a tetrahedral framework formed by zinc ions and imidazolate ligands with sodalite topology is the most extensively studied [9]. Substantial works have been done on synthesizing ZIF-8 for gas sorption/separation, catalysis, electrochemical biosensor, as well as functionalized thin films, etc. [10-14]. ZIF-8 could be an attractive sorbent for arsenic removal because of its ultrahigh porosity, high chemical stability and hydrophobic nature.

In this study, the feasibility of adsorptive removal of arsenic by ZIF-8 nanoparticles was systematically investigated. ZIF-8 nanoparticles were synthesized via a facile method at room temperature. The prepared ZIF-8 nanoparticles were characterized by field emission scanning electron microscope (FESEM), transmission electron microscopy (TEM), powder X-ray diffraction (PXRD), Nitrogen sorption and Zeta potential. The performance on arsenic adsorption was assessed in detail in terms of adsorption kinetics and isotherm. The influences of some key operational parameters, such as solution $\mathrm{pH}$, ionic strength and initial arsenic concentrations on arsenic removal were investigated. Moreover, the adsorption mechanism of arsenic on ZIF-8 nanoparticles was analyzed by Fourier transform infrared spectroscopy (FT-IR), Zeta potentials and X-ray photoelectron spectroscopy (XPS). The results could provide new insights to the application of MOFs for water treatment.

\section{Materials and methods}

\subsection{Materials}

All chemicals were of analytical grade and used without further purification. $\mathrm{As}(\mathrm{III})$ and $\mathrm{As}(\mathrm{V})$ stock solutions were prepared by dissolving $\mathrm{NaAsO}_{2}$ and $\mathrm{Na}_{3} \mathrm{AsO}_{4} \cdot 12 \mathrm{H}_{2} \mathrm{O}$ respectively in Ultrapure water, and stored in the dark at $4{ }^{\circ} \mathrm{C}$. Stock solutions were then diluted with Ultra-pure water to predetermined concentrations for following experiments. All volumetric flasks and vessels were cleaned by soaking in $10 \% \mathrm{HNO}_{3}$ for at least $24 \mathrm{~h}$ and rinsed several times with deionized (DI) water.

\subsection{Synthesis of ZIF-8 nanoparticles}

ZIF-8 nanoparticles were synthesized at room temperature following a slightly modified method in the literature [15]. Scheme 1

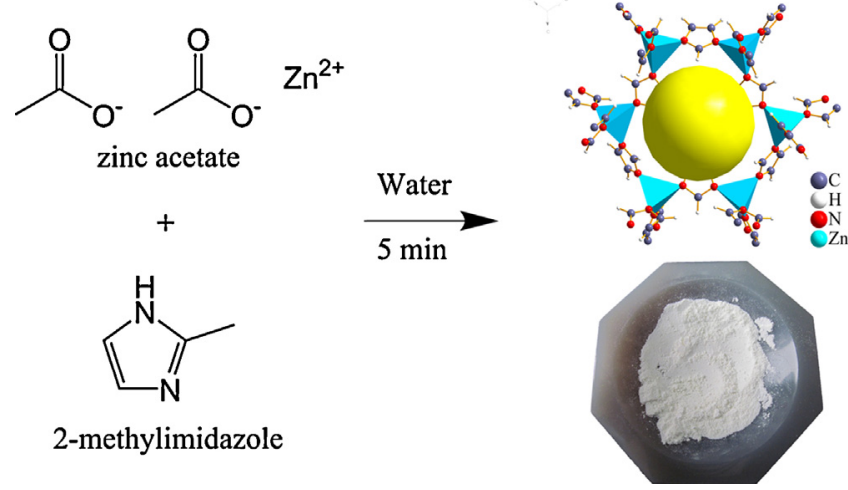

Scheme 1. Schematic of synthesis of ZIF-8 nanoparticles in water at room temperature.

shows the major steps for the preparation of ZIF-8 nanoparticles. Typically, $0.863 \mathrm{~g}$ of $\mathrm{Zn}(\mathrm{OAc})_{2}$ and $22.700 \mathrm{~g}$ 2-methylimidazole were first dissolved in $8 \mathrm{~g}$ and $80 \mathrm{~g}$ DI water, respectively. The two solutions were then mixed under stirring at room temperature $\left(\sim 25 \pm 2{ }^{\circ} \mathrm{C}\right)$. The molar ratio of $\mathrm{Zn}^{2+}: 2$-methylimidazole: $\mathrm{H}_{2} \mathrm{O}$ in the mixture was of 1:70:1238. After 5 min of stirring, the product was collected by centrifugation at $7500 \mathrm{rpm}$ for $30 \mathrm{~min}$, and then washed with DI water for several times. The obtained ZIF-8 nanoparticles were dried in an oven at $80^{\circ} \mathrm{C}$ for $24 \mathrm{~h}$ to remove residual water and then kept in a desiccator for use.

\subsection{Batch arsenic adsorption experiments}

All the arsenic adsorption experiments were carried out at $25.0 \pm 1^{\circ} \mathrm{C}$. Before adsorption experiments, the ZIF-8 nanoparticles suspension was treated in an ultrasound bath for $5 \mathrm{~min}$ to avoid the aggregation of ZIF-8 nanoparticles. The adsorption kinetics tests were performed in a glass beaker, which contained $500 \mathrm{~mL}$ of arsenic solution. The initial concentration of arsenic in the solution was of $20 \mathrm{mg} / \mathrm{L}$. The $\mathrm{pH}$ of the arsenic solution was adjusted to $7.0 \pm 0.1$ using $0.1 \mathrm{M} \mathrm{HCl}$ and $\mathrm{NaOH}$. After $0.1 \mathrm{~g}$ of sorbent was introduced into the glass beaker, the solution was mixed by a magnetic stirrer at $170 \mathrm{rpm}$. The kinetics tests were run for $48 \mathrm{~h}$, and approximately $4 \mathrm{~mL}$ of suspension was taken at specific time intervals to measure arsenic concentration. Each kinetics test was performed in triplicate and the mean value was reported.

Adsorption isotherm experiments were conducted in $250 \mathrm{~mL}$ shaking flasks containing $100 \mathrm{~mL}$ of arsenic solution. The initial concentration of arsenic varied from $5 \mathrm{mg} / \mathrm{L}$ to $100 \mathrm{mg} / \mathrm{L}$ and the $\mathrm{pH}$ of solution was adjusted to $7.0 \pm 0.1$ by diluted $\mathrm{NaOH}$ and $\mathrm{HCl}$. After $20 \mathrm{mg}$ of ZIF-8 nanoparticles was added to the arsenic solution, these flasks were shacked on a shaker for $24 \mathrm{~h}$ at $170 \mathrm{rpm}$. In order to investigate the ionic strength effect on arsenic adsorption, 0.01 and $0.1 \mathrm{M} \mathrm{NaCl}$ were added into the solution respectively. To assess the effect of co-existing anions on the removal of arsenic, $\mathrm{NaNO}_{3}, \mathrm{Na}_{2} \mathrm{SO}_{4}, \mathrm{Na}_{2} \mathrm{CO}_{3}$ and $\mathrm{Na}_{3} \mathrm{PO}_{4} \cdot 12 \mathrm{H}_{2} \mathrm{O}$ at three different concentration levels $(0,2.7$, and $27 \mathrm{mM})$ were selected to assess the competitive adsorption in a specific arsenic concentration $(20 \mathrm{mg} / \mathrm{L})$. Each kinetics test was performed in triplicate and the mean value was reported.

\subsection{Analytical methods}

The surface morphologies and elemental compositions of ZIF-8 nanoparticles were examined by FESEM (SU-8020, Hitachi, Japan) coupled with Energy-dispersive X-ray spectroscopy (EDX) (INCA X, Oxford, Japan) and TEM (H-7500; Hitachi, Japan). The PXRD analysis was carried out on a diffractometer (AXS, Brucker, Germany) 

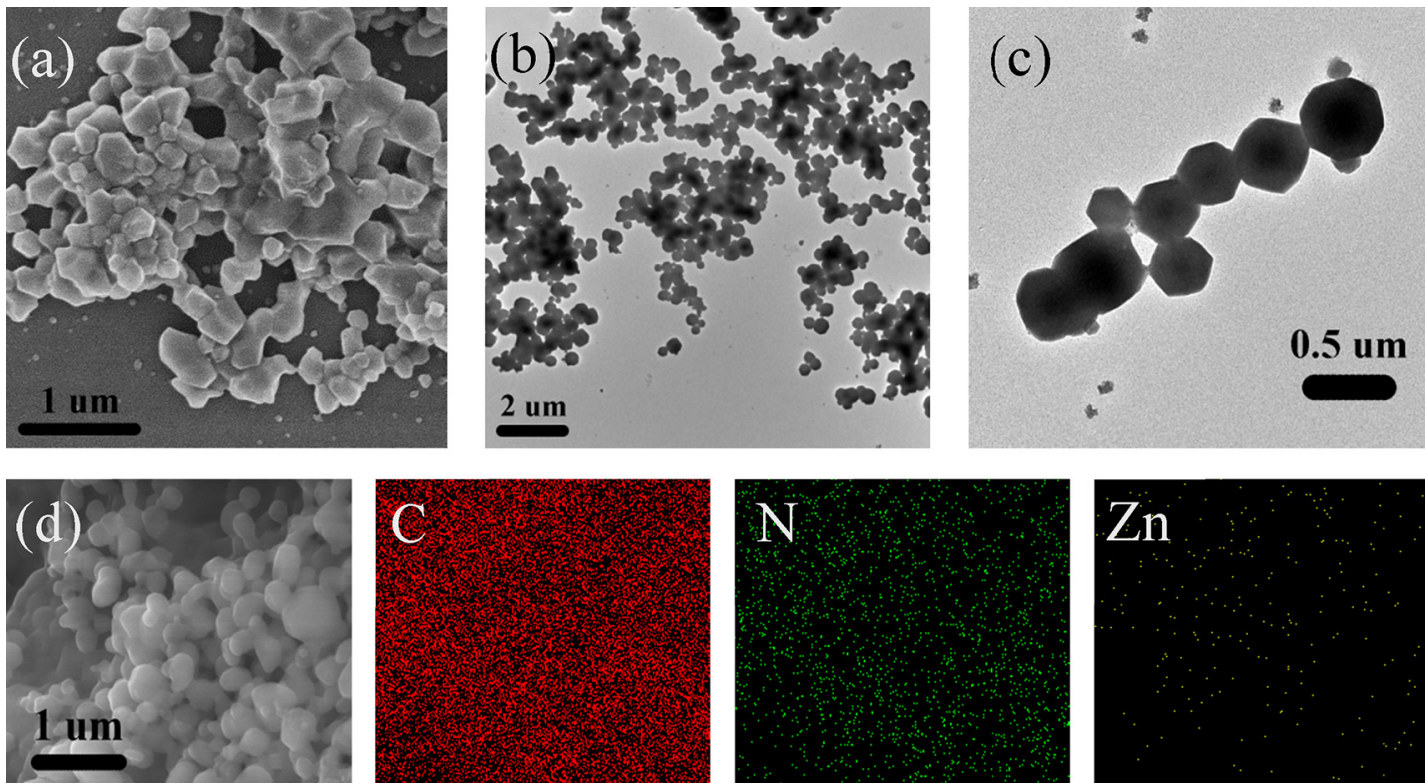

Fig. 1. (a) FESEM image of ZIF-8 nanoparticles, (b, c) TEM image of ZIF-8 nanoparticles, and (d) C, N, Zn elemental maps of ZIF-8 nanoparticles.

with Cu target $(40 \mathrm{kV}, 40 \mathrm{~mA}, \lambda=1.54059 \AA)$ from $3^{\circ}$ to $55^{\circ}$. The $\mathrm{pH}$ of solution was measured by a pH meter (Orion 3Star, Thermo, USA). The specific surface area and pore volume of the sorbent were analyzed on a Micrometrics gas adsorption analyzer instrument (ASAP2020HD88; Micromeritics, USA). Prior to the measurement, the sample was degassed at $150^{\circ} \mathrm{C}$ for $6 \mathrm{~h}$ in the vacuum line. The functional groups on the sorbents were identified at room temperature by FT-IR (Tenson 27; Bruker, Germany) in transmission mode. FT-IR spectra were measured on $\mathrm{KBr}$ pellets prepared by pressing mixtures of $1 \mathrm{mg}$ dry sorbent and $100 \mathrm{mg}$ spectrometry grade $\mathrm{KBr}$. Zeta-potential of the sorbent at different $\mathrm{pH}$ was measured by a Zeta-potential analyzer (DelsaNano C; Beckman Coulter Ltd., USA). The semi-quantitative surface chemical composition data of the sorbent were examined by XPS (Kratos Analytical, Manchester, UK) using an AXIS Ultra spectrometer with an Al K anode (1486.6 eV photon energy, $0.05 \mathrm{eV}$ photon energy resolution, $300 \mathrm{~W}$ ).

Arsenic concentration was measured by an inductively coupled plasma atomic emission spectroscopy machine (ICP-OES, Optima 7100 DV; Perkin Elmer Co., USA) with an inductive coupled plasma mass spectrometer (ICP-MS; SCIEX ELAN DRCe Norwalk, Perkin Elmer Co., USA) for low arsenic concentration. Prior to analysis, samples were filtered by a $0.22 \mu \mathrm{m}$ membrane filter and acidified with concentrated $\mathrm{HNO}_{3}$. All samples were analyzed within $24 \mathrm{~h}$ after collection.

\section{Results and discussion}

\subsection{Characterization of ZIF-8 nanoparticles}

Fig. 1a-c presents the FESEM and TEM images of ZIF-8 nanoparticles which reveal that the particle sizes are of $200-400 \mathrm{~nm}$. The synthesized ZIF-8 nanoparticles have non-uniform shapes and sizes unlike those synthesized via conventional hydrothermal method with a clear rhombic dodecahedron morphology, although some expected ZIF-8 nanoparticles with hierarchical structure can be observed from Fig. 1c [7]. This might be due to the faster growth kinetics in the present fabrication method compared with hydrothermal method [16]. Although morphology may affect the adsorption performance of an adsorbent, specific surface area and the amount of adsorptive sites of adsorbents are more dominant factor [2,4]. Elemental mapping (Fig. 1d) confirms the homogeneous distribution of $\mathrm{C}, \mathrm{N}$, and $\mathrm{Zn}$ elements in ZIF-8 nanoparticles. The percentage of $\mathrm{Zn}, \mathrm{N}$ and $\mathrm{C}$ elements were of $22.80 \mathrm{wt} \%$, $31.82 \mathrm{wt} \%$ and $43.64 \mathrm{wt} \%$, respectively.

$\mathrm{N}_{2}$ adsorption-desorption isotherm of ZIF-8 nanoparticles is presented in Fig. 2a. It exhibits type-I isotherms. The increase in the volume adsorbed at very low relative pressures indicates a microporous structure [17]. The BET specific surface area and total pore volume of synthesized ZIF-8 nanoparticles were calculated to be of $1063.5 \mathrm{~m}^{2} / \mathrm{g}$ and $0.57 \mathrm{~cm}^{3} / \mathrm{g}$, respectively, which are very close to the values that reported from others $[10,11]$. This means ZIF-8 nanoparticles show a remarkable porous structure. Additionally, as shown in Fig. $2 \mathrm{~b}$, the pore sizes are narrowly distributed between $0.8 \mathrm{~nm}$ and $1.60 \mathrm{~nm}$, indicating that ZIF-8 nanoparticles have a highly uniform pore structure.

\subsection{Adsorption kinetics}

Fig. 3a and $b$ shows the variation of adsorbed $\mathrm{As}(\mathrm{III})$ and $\mathrm{As}(\mathrm{V})$ on ZIF-8 nanoparticles as a function of reaction time, respectively. The adsorption of $\mathrm{As}(\mathrm{III})$ and $\mathrm{As}(\mathrm{V})$ on $\mathrm{ZIF}-8$ nanoparticles is fast in the beginning, and then quickly levels off. The time required to reach the adsorption equilibrium for $\mathrm{As}(\mathrm{V})$ was only $7 \mathrm{~h}$ while $13 \mathrm{~h}$ for $\mathrm{As}$ (III). In order to make sure that adsorption equilibrium is achieved, adsorption time of the following experiments was set at $24 \mathrm{~h}$.

To analyze the adsorption kinetics, pseudo-first-order and pseudo-second-order models were used to describe the sorption kinetic data. The calculated kinetic constants are shown in Table S1 (Supporting Information). As shown in Fig. 3a and b, the pseudo-second-order model fits the experiment data better than the pseudo-first-order model. The adsorption rate constant $\left(k_{2}\right)$ of $\mathrm{As}(\mathrm{V})$ is about 4 times higher than that of $\mathrm{As}(\mathrm{III})$, which means adsorption of $\mathrm{As}(\mathrm{V})$ on ZIF-8 nanoparticles is much faster than As(III). The reason might be that the surface of ZIF-8 nanoparticles has a net positive charge at neutral condition as shown in Fig. 2b, which could attract $\mathrm{As}(\mathrm{V})$ more easily than uncharged $\mathrm{As}(\mathrm{III})$ $[18,19]$.

The pseudo-first-order and pseudo-second-order models can well describe the overall rate of adsorption. However, both models 
(a)

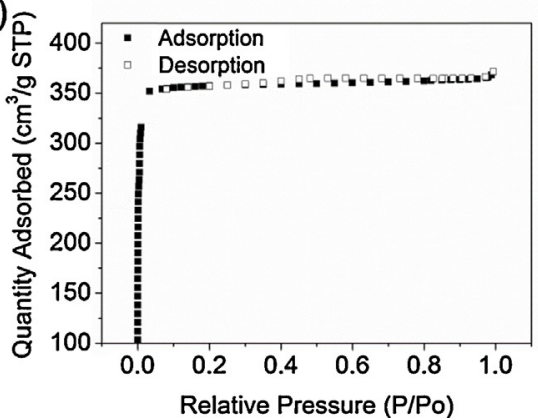

(b)

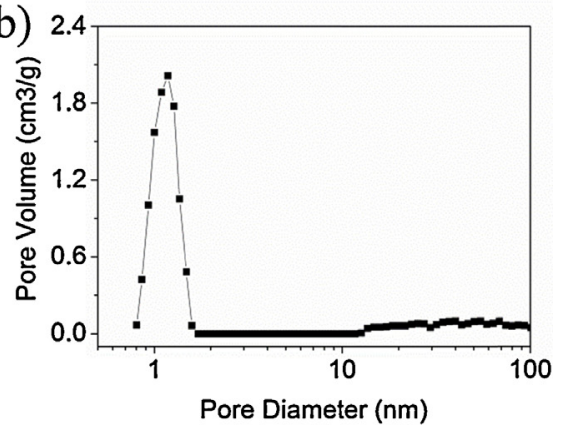

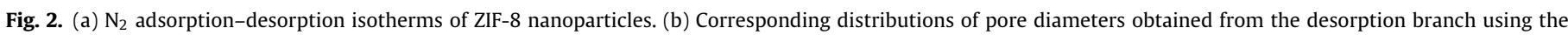
density functional theory (DFT) method.

provide little information about whether external or internal diffusion is the dominant rate limiting step during the adsorption process. In order to identify the arsenic transport process on ZIF-8 nanoparticles, the intraparticle diffusion model was used to analyze the rate controlling step based on the kinetics data. As shown in Fig. $3 c$ and d, three linearity plots were showed in the adsorption process, implying that three diffusion steps existed in the ZIF-8 nanoparticles adsorption [20]: (1) sorbate transfers from the boundary film to surface of sorbent (external transfer step), (2) sorbate transfers from the sorbent surface to intraparticle active site or binding site (intraparticle diffusion step), (3) sorption of the sorbate diffuse on the active or binding sites of sorbent until saturation (final equilibrium step). According to the intraparticle diffusion model, the slope of the linearity plot was defined as the diffusion rate constant, and the diffusion rate constants of the three steps are summarized in Table S1 (Supporting Information) with an order of $k_{1}>k_{2}>k_{3}$ for both $\mathrm{As}(\mathrm{V})$ and $\mathrm{As}(\mathrm{III})$. It means that the adsorption rate of external diffusion, which starts at onset of the adsorption process, is the fastest. Therefore, it can be deduced that the present adsorption rates are mainly controlled by the pore (intraparticle) diffusion rather than the boundary layer (external) diffusion [21,22].

\subsection{Adsorption isotherms}

The adsorption capacity of $\mathrm{As}(\mathrm{III})$ and $\mathrm{As}(\mathrm{V})$ on ZIF-8 nanoparticles at different ionic strengths were investigated via adding $\mathrm{NaCl}$ of $0,0.01,0.1 \mathrm{M}$ into the arsenic solutions, respectively. As shown in Fig. 4, the adsorption of both $\mathrm{As}(\mathrm{III})$ and $\mathrm{As}(\mathrm{V})$ is not significantly affected by the increase of ionic strength. Meanwhile, as indicated in Fig. S1 (Supporting Information), after As(III) and As(V) loading, the $\mathrm{pH}_{\mathrm{IEP}}$ of ZIF-8 nanoparticles decreased from 9.6 to about 7.0 and 5.9 , respectively. These results indicate that inner-sphere surface complexes may be occurred during the arsenic adsorption process on ZIF-8 nanoparticles, because when outer-sphere surface complexes are formed, the arsenic adsorption is strongly dependent on ionic strength and cannot shift the $\mathrm{pH}_{\mathrm{IEP}}$ of $\mathrm{ZIF}-8$ nanoparticles $[23,24]$.
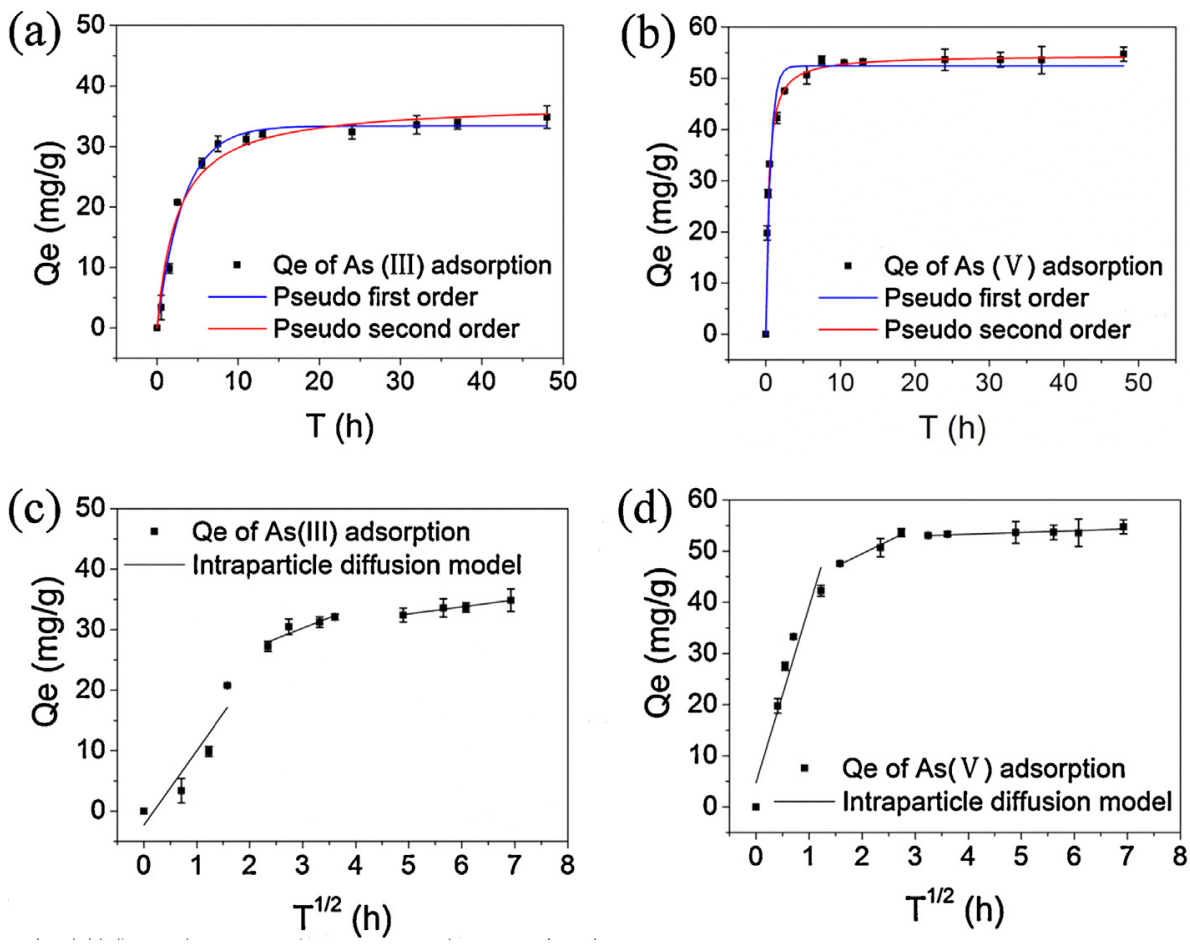

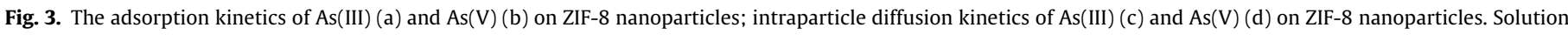
$\mathrm{pH}=7.0 \pm 0.1$, initial arsenic concentration $=20 \mathrm{mg} / \mathrm{L}$, adsorbent dose $=200 \mathrm{mg} / \mathrm{L}$, rotating speed $=170 \mathrm{rpm}$ and $T=25.0 \pm 1^{\circ} \mathrm{C}$. 

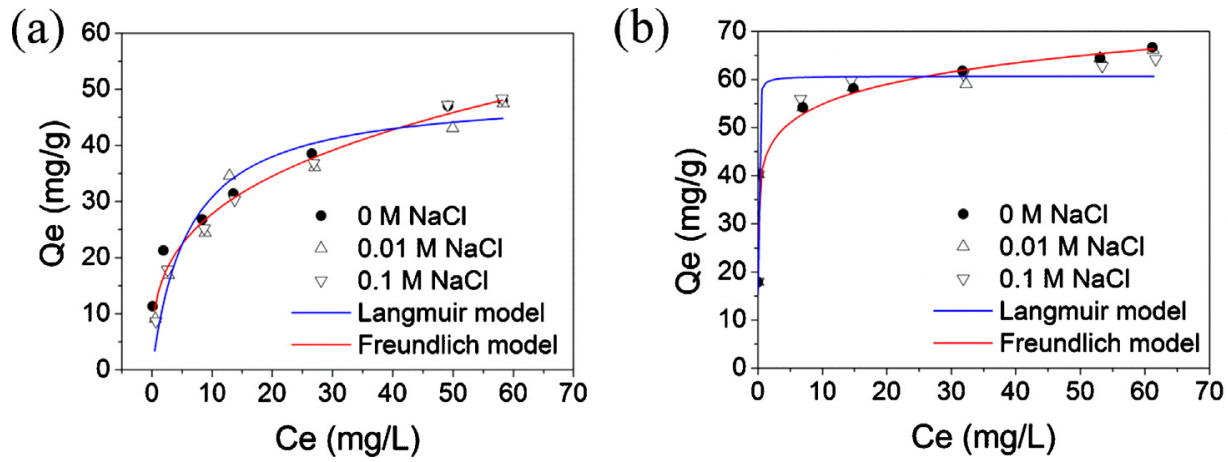

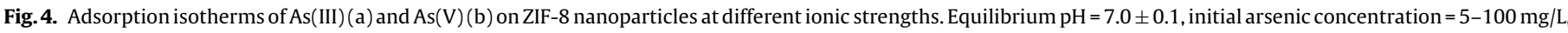
adsorbent dose $=200 \mathrm{mg} / \mathrm{L}$, rotating speed $=170 \mathrm{rpm}$ and $T=25.0 \pm 1^{\circ} \mathrm{C}$.

Table 1

Comparison of $\mathrm{As}(\mathrm{III})$ and $\mathrm{As}(\mathrm{V})$ adsorption capacity of ZIF-8 nanoparticles with other adsorbents in the references.

\begin{tabular}{|c|c|c|c|c|c|}
\hline \multirow[t]{2}{*}{ Adsorbent } & \multirow[t]{2}{*}{$\mathrm{pH}$} & \multirow[t]{2}{*}{ Concentration range $(\mathrm{mg} / \mathrm{L})$} & \multicolumn{2}{|c|}{ Adsorption capacity (mg/g) } & \multirow[t]{2}{*}{ Reference } \\
\hline & & & $\mathrm{As}(\mathrm{III})$ & $\operatorname{As}(\mathrm{V})$ & \\
\hline Iron-chitosan flakes & 7.0 & $1-10$ & 16.15 & 22.47 & {$[28]$} \\
\hline Iron-coated zeolite & 4.0 & $0-20$ & - & 0.68 & [29] \\
\hline Activated alumina & 7.0 & $0-250$ & 19.63 & - & [30] \\
\hline Fe-Zr binary oxide & 7.0 & $0.5-15$ & - & 9.36 & [31] \\
\hline Fe-Mn binary oxide & 6.9 & $0-40$ & 100.4 & 53.9 & {$[32]$} \\
\hline CuO nanoparticles & 8.0 & $0.1-100$ & 26.9 & 22.6 & [19] \\
\hline Treated laterite & 7.0 & $0.2-20.0$ & 9.4 & 21.6 & [33] \\
\hline $\mathrm{ZrO}_{2} \cdot x \mathrm{H}_{2} \mathrm{O}$ & 7.0 & $0.3-100$ & 47.1 & 29.3 & {$[34]$} \\
\hline $\mathrm{Fe}_{3} \mathrm{O}_{4}$ & 7.0 & $0-100$ & 5.68 & 4.78 & [35] \\
\hline ZIF-8 nanoparticles & 7.0 & $0-100$ & 49.49 & 60.03 & This study \\
\hline
\end{tabular}
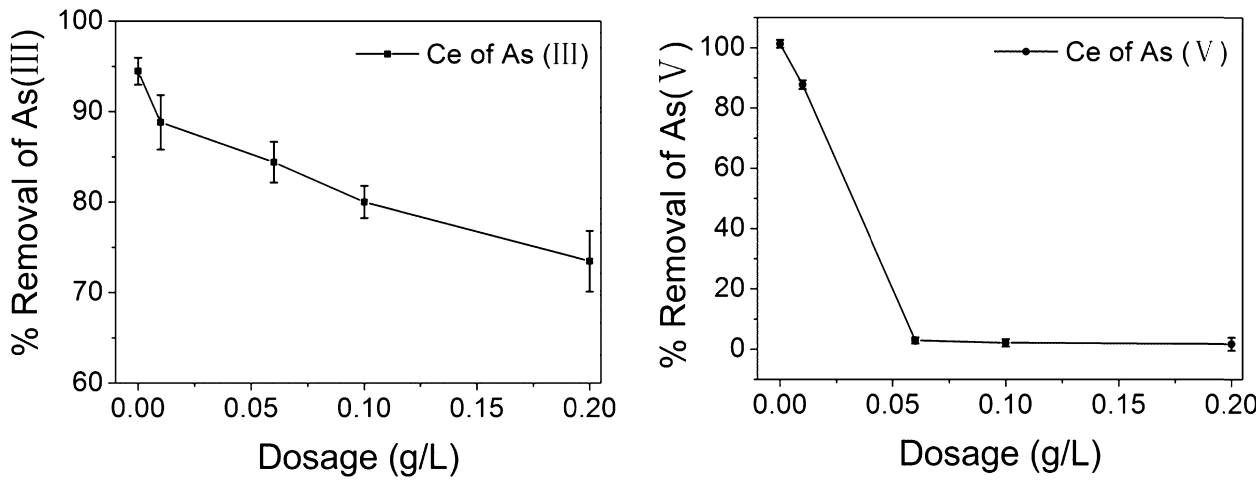

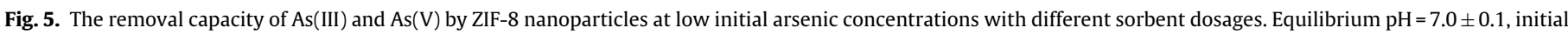
arsenic concentration $=100 \mu \mathrm{g} / \mathrm{L}$ and $T=25.0 \pm 1{ }^{\circ} \mathrm{C}$.

To better understand the arsenic adsorption capacity of ZIF8 nanoparticles, Langmuir and Freundlich isotherm models were applied here to explain the adsorption equilibriums.

The Langmuir isotherm [25]:

$Q_{e}=\frac{Q^{0} K_{L} C_{e}}{1+K_{L} C_{e}}$

The Freundlich isotherm [26]:

$Q_{e}=K_{F} C_{e}^{1 / n}$

where $Q_{e}$ is the amount of adsorbed arsenic on per gram of sorbent $(\mathrm{mg} / \mathrm{g}) ; C_{e}$ is the equilibrium concentration of adsorbate in the solution $(\mathrm{mg} / \mathrm{L}) ; Q^{0}$ is the maximum amount of adsorbate uptake per unit mass of the sorbent $(\mathrm{mg} / \mathrm{g}) ; K_{L}$ is the Langmuir equilibrium constant $(\mathrm{L} / \mathrm{mg}) ; K_{F}$ is the relative adsorption capacity $(\mathrm{mg} / \mathrm{g})$ and $n$ is the intensity of adsorption.

The parameters of the two adsorption isotherms for As(III) and $\mathrm{As}(\mathrm{V})$ adsorption on ZIF-8 nanoparticles are summarized in

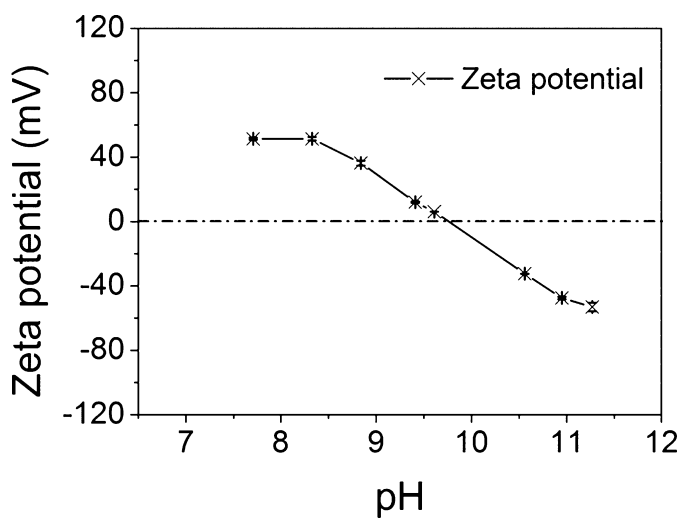

Fig. 6. The isoelectric point of the synthesized ZIF-8 nanoparticles. 

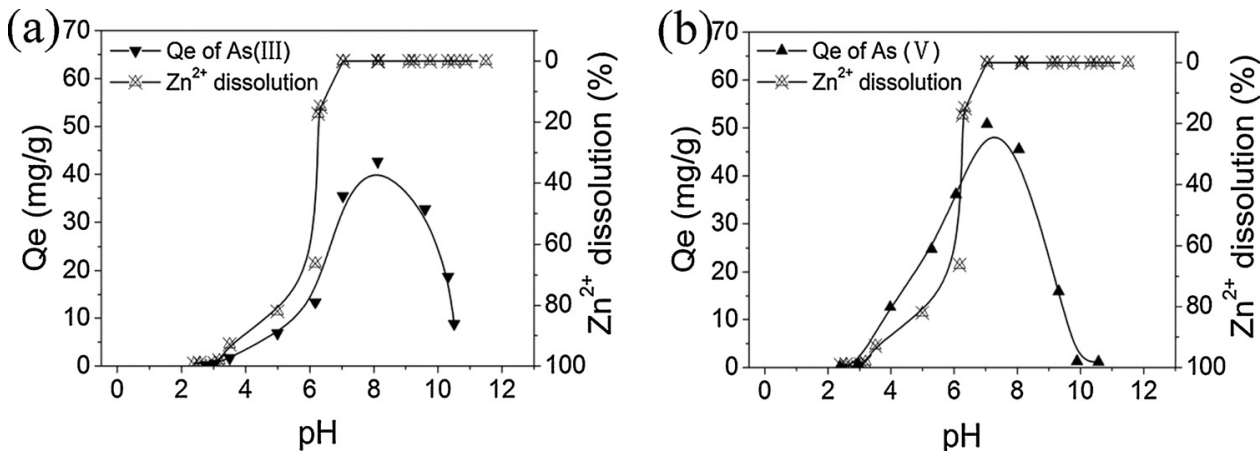

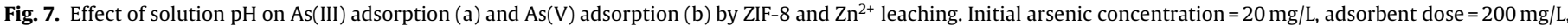
rotating speed $=170 \mathrm{rpm}$ and $T=25.0 \pm 1{ }^{\circ} \mathrm{C}$.

Table S2. The adsorption equilibrium data is better fitted by the Freundlich model than Langmuir model, which means a heterogeneous sorption [27]. The maximum adsorption capacities for As(III) and $\mathrm{As}(\mathrm{V})$ from Langmuir model were determined at $49.49 \mathrm{mg} / \mathrm{g}$ and $60.03 \mathrm{mg} / \mathrm{g}$, respectively. As shown in Table 1, the adsorption capacities of ZIF-8 nanoparticles for both $\mathrm{As}(\mathrm{III})$ and $\mathrm{As}(\mathrm{V})$ are higher than these of most other sorbents reported in the literature. This implies that the ZIF-8 nanoparticles can be a potential sorbent for arsenic removal.

The adsorption capacity of ZIF- 8 at low arsenic concentration is also extremely important for practical drinking water treatment. Therefore, the removal efficiency of arsenic at low arsenic concentration $(100 \mu \mathrm{g} / \mathrm{L})$ was also studied. Fig. 5 shows that the $\mathrm{As}(\mathrm{V})$ concentration in the solution decreases dramatically to $2.8 \mu \mathrm{g} / \mathrm{L}$ from $100 \mu \mathrm{g} / \mathrm{L}$ just using $0.06 \mathrm{~g} / \mathrm{L}$ of ZIF-8, which is much lower than arsenic MCL of drinking water. However, As(III) concentration can only decrease to $73 \mu \mathrm{g} / \mathrm{L}$ from the initial $100 \mu \mathrm{g} / \mathrm{L}$ even at a high ZIF-8 dosage of $0.2 \mathrm{~g} / \mathrm{L}$.

\subsection{Effect of $p H$ on arsenic sorption and stability of ZIF-8 nanoparticles}

Solution $\mathrm{pH}$ influences both the binding sites on the sorbent surface and distribution of arsenic species, thus it may have an impact on arsenic adsorption. However, the determination of the isoelectric point $\left(\mathrm{pH}_{\mathrm{IEP}}\right)$ can well explain and optimize arsenic uptake on adsorbents at different $\mathrm{pH}$ ranges. Fig. 6 illustrates the relationship between Zeta potential of ZIF- 8 and solution $\mathrm{pH}$. It can be seen that $\mathrm{pH}_{\text {IEP }}$ of the ZIF-8 nanoparticles is around 9.6, the value of $\mathrm{pH}_{\text {IEP }}$ implies that the surface of the ZIF-8 nanoparticles is positively charged when solution $\mathrm{pH}$ is below 9.6, while the surface of ZIF8 nanoparticles becomes negatively charged at solution $\mathrm{pH}$ above 9.6. Fig. 7a and $\mathrm{b}$ shows the arsenic adsorption on ZIF-8 at different solution $\mathrm{pH}$. It can be seen that the adsorption of $\mathrm{As}(\mathrm{III})$ and $\mathrm{As}(\mathrm{V})$ on ZIF-8 are obviously dependent on the solution pH. Maximal adsorption of $\mathrm{As}(\mathrm{V})$ on ZIF-8 is achieved at neutral condition, mainly because the surface of ZIF- 8 nanoparticles is positively charged at the $\mathrm{pH}$. The optimal $\mathrm{pH}$ for As(III) adsorption is slightly higher than that for $\operatorname{As}(\mathrm{V})$. The small difference might be attributed to a higher $\mathrm{p} K_{\mathrm{a}}=9.2$ for $\mathrm{As}(\mathrm{III})$ compared to the $\mathrm{p} K_{\mathrm{a} 2}=6.94$ for $\mathrm{As}(\mathrm{V})$ (Fig. S2). Similar results were also observed on other sorbent by Ren et al. [36]. This means that there is no need to adjust $\mathrm{pH}$ solution for most water treatment, particularly for drinking water, which is highly desirable for practical application. The adsorption of both As(III) and $\mathrm{As}(\mathrm{V})$ decreases remarkably as the solution $\mathrm{pH}$ increases from neutral to basic range. It can be explained by that positive charge density on ZIF-8 decreases with increasing solution $\mathrm{pH}$ and eventually turns to negative resulting in electrostatic repulsion between arsenic and ZIF-8 [37]. However, the adsorption performance of ZIF-8 decreases dramatically under acidic condition from $\mathrm{pH} 2$ to

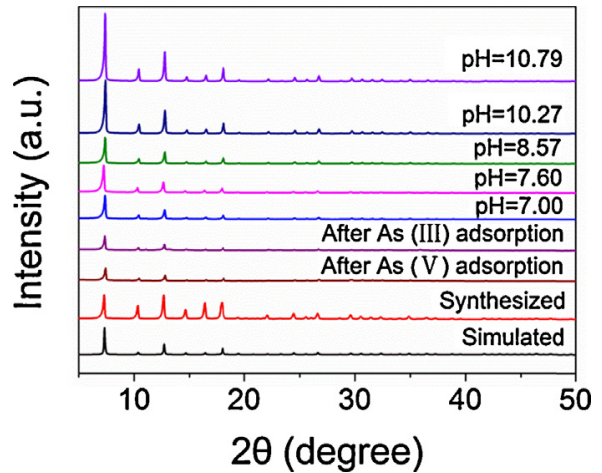

Fig. 8. XRD diffraction patterns of the synthesized ZIF- 8 at different $\mathrm{pH}$ and used ZIF-8 after arsenic adsorption at pH 7.0.

pH 6 although the sorbent becomes more positively charged. We observed that ZIF-8 became unstable under acidic $\mathrm{pH}$ conditions and high concentration of $\mathrm{Zn}^{2+}$ was released into the solution indicating the dissolution of ZIF-8 nanoparticles. As shown in Fig. 7 , more ZIF-8 nanoparticles are dissolved with decreasing the $\mathrm{pH}$ of the solution, leading to the decline of the adsorption capacity of ZIF-8 for As(III) and As(V). In contrast, ZIF-8 is very stable in neutral and basic conditions and no $\mathrm{Zn}^{2+}$ was detected.

Fig. 8 presents XRD patterns of the ZIF-8 nanoparticles. It can be seen that the synthesized of ZIF- 8 is highly crystal and the XRD patterns are in good agreement with the literature [7]. Furthermore, the crystallinity of ZIF-8 nanoparticles retains well at $\mathrm{pH}>7$, which provides further evidences that ZIF-8 nanoparticles are stable in neutral and alkaline conditions. It is worth noting that the crystallinity of ZIF-8 nanoparticles also retains very well after arsenic adsorption although the intensities of the X-ray peaks of ZIF-8 nanoparticles are slightly lower than those of virgin ZIF-8

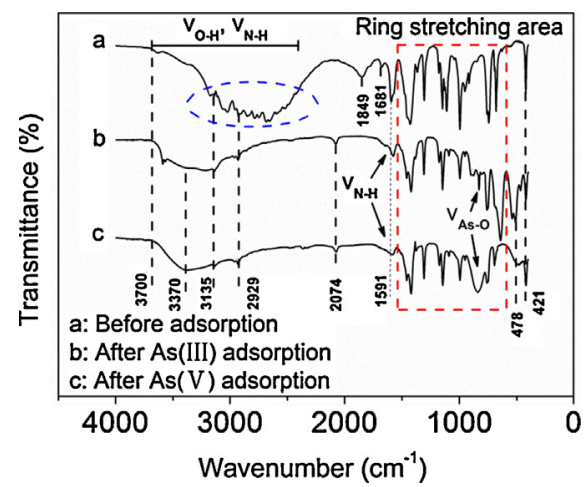

Fig. 9. FT-IR spectra of ZIF-8 nanoparticles before and after $\mathrm{As}(\mathrm{III})$ and $\mathrm{As}(\mathrm{V})$ adsorption. 


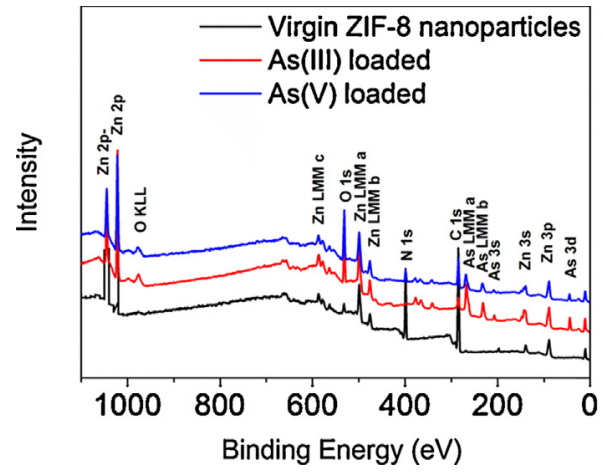

Fig. 10. XPS wide scan spectra of ZIF-8 nanoparticles before and after $\mathrm{As}(\mathrm{III})$ and $\mathrm{As}(\mathrm{V})$ adsorption.

nanoparticles. The decrease might be caused by the adsorbed arsenic on the surface of ZIF-8 nanoparticles.

\subsection{Adsorption mechanisms}

\subsubsection{FT-IR analysis}

The FT-IR spectra of ZIF-8 nanoparticles before and after arsenic adsorption in the range of $4000-400 \mathrm{~cm}^{-1}$ are plotted in Fig. 9. For (a)

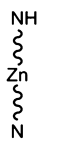

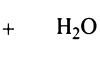<smiles>CCCCCCCC</smiles><smiles>NCC(O)C(N)=O</smiles>

(b)

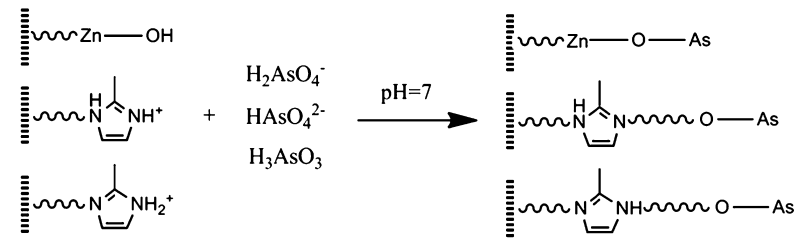

Fig. 12. Schematic diagram for the possible complexes of $\mathrm{As}(\mathrm{III})$ and $\mathrm{As}(\mathrm{V})$ formed on ZIF-8 nanoparticles.

the FT-IR spectra of virgin ZIF-8 nanoparticles (Fig. 9a), the strong band in the spectral region of $2500-3000 \mathrm{~cm}^{-1}$ could be ascribed to $\mathrm{C}-\mathrm{H}, \mathrm{N}-\mathrm{H}$ and $\mathrm{O}-\mathrm{H}$ stretching vibrations of methyl, hydroxyl and amine groups on ZIF-8 nanoparticles [38]. Additionally, it can be observed that many miscellaneous weak peaks existed in the area of blue oval, this may due to the formation of protonated groups by water clusters. The peaks at 1681 and $1591 \mathrm{~cm}^{-1}$ are attributed to the bending and stretching $\mathrm{N}-\mathrm{H}$ vibration of the imidazole, respectively [39]. A peak at $1849 \mathrm{~cm}^{-1}$ can be assigned as the $\mathrm{C}=\mathrm{N}-\mathrm{H}$
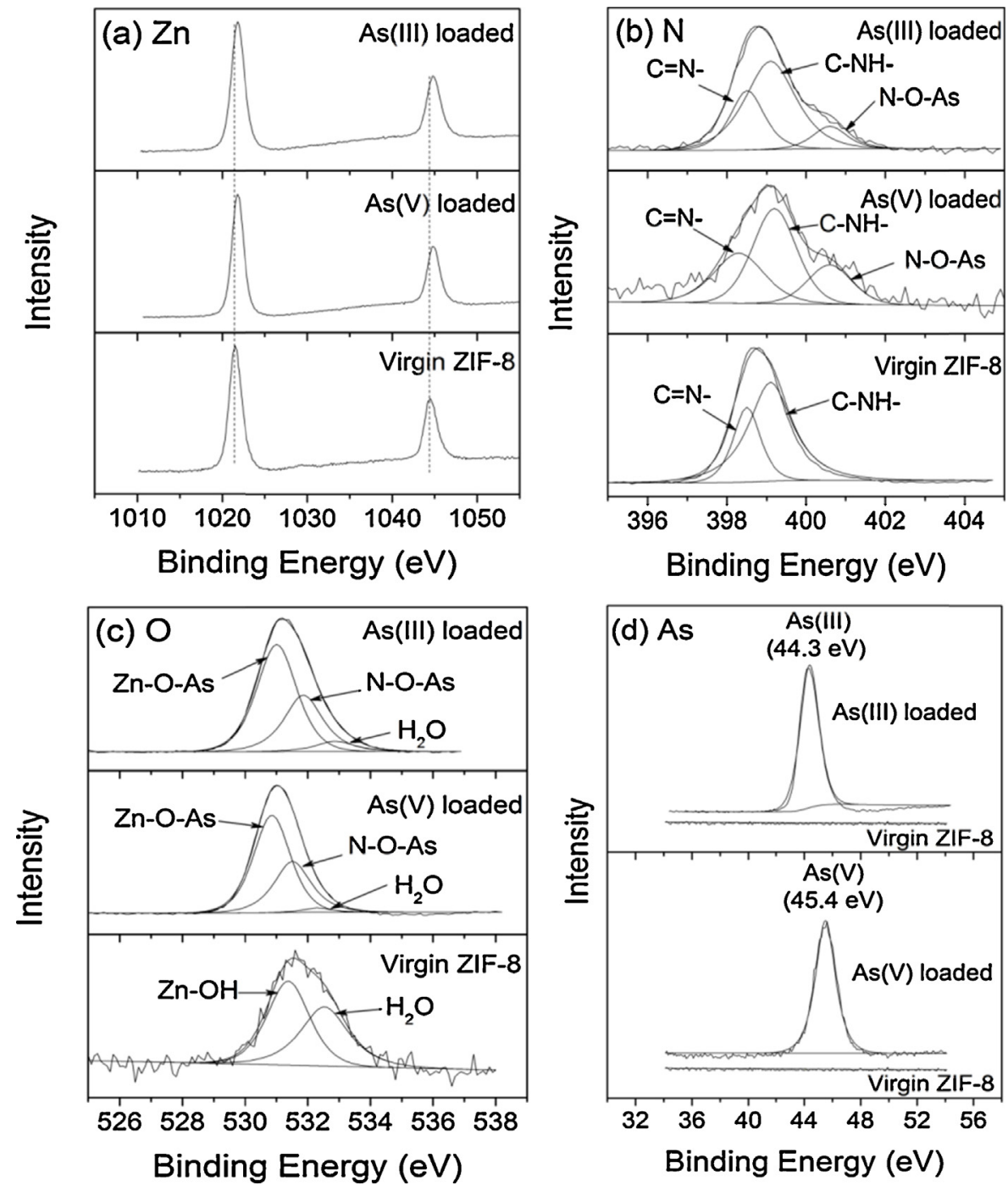

Fig. 11. XPS (a) Zn 2p, (b) N 1s, (c) O 1s and (d) As 3d core-level spectra of ZIF-8 nanoparticles before and after As(III) and As(V) adsorption. 

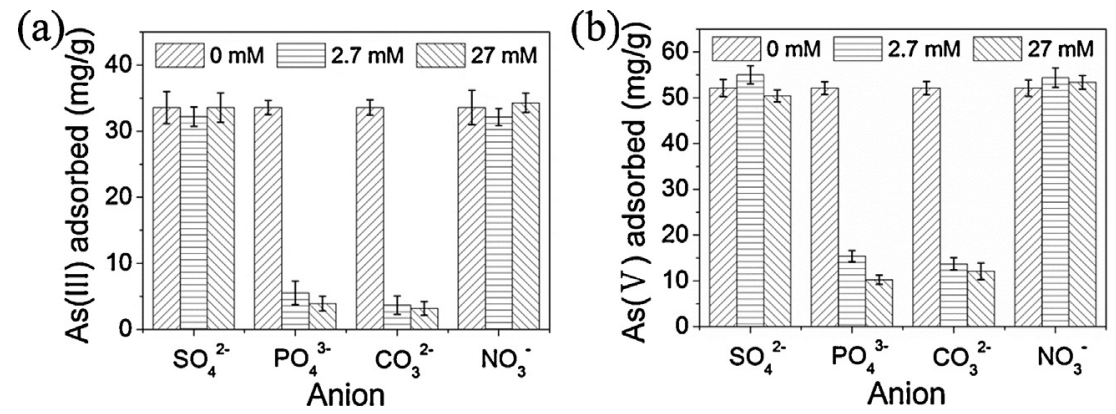

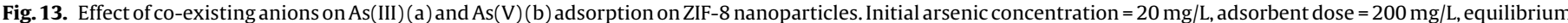
$\mathrm{pH}=7.0 \pm 0.1$, rotating speed $=170 \mathrm{rpm}$ and $T=25.0 \pm 1^{\circ} \mathrm{C}$.

stretching of the imidazole, which accompanied with a wide strong peak between 2300 and $2500 \mathrm{~cm}^{-1}$, whereas the intense and convoluted bands at $1350-1500 \mathrm{~cm}^{-1}$ are associated with the entire ring stretching [40]. In addition, we also can observe the $\mathrm{Zn}-\mathrm{N}$ stretch mode at $421 \mathrm{~cm}^{-1}$ [41].

For the spectra of ZIF-8 after the arsenic adsorption (Fig. 9b and c), the intensity of $\mathrm{C}-\mathrm{H}, \mathrm{N}-\mathrm{H}$ and $\mathrm{O}-\mathrm{H}$ stretch at $2500-3500 \mathrm{~cm}^{-1}$ clearly weakened and the peaks in this region became smooth. It is reasonable to postulate that protonated groups acting as Lewis acid sites formed arsenic complexes [42]. Meanwhile, the peaks at $1591 \mathrm{~cm}^{-1}$ and $1849 \mathrm{~cm}^{-1}$ which assigned to $\mathrm{N}-\mathrm{H}$ stretching vibration demonstrated red shift $\left(-12 \mathrm{~cm}^{-1}\right)$ and significant blue shift $\left(+225 \mathrm{~cm}^{-1}\right)$ after arsenic adsorption, respectively. Meantime, the bond at $1581 \mathrm{~cm}^{-1}$ disappeared. These results indicate that hydroxyl and amine groups might be involved in the adsorption. In addition, two new peaks are detected at $826 \mathrm{~cm}^{-1}$ and $842 \mathrm{~cm}^{-1}$, respectively, which can be corresponded to the stretching vibration of As-O bond $[43,44]$. At around $478 \mathrm{~cm}^{-1}$, a strong band appears which could be attributed to the vibration of $\mathrm{Zn}-\mathrm{O}$ after adsorption, proposing that arsenic complex with zinc are also formed [45]. In addition, there is a highly intense peak at around $3370 \mathrm{~cm}^{-1}$, demonstrating that new $\mathrm{NH}-\mathrm{O}$ bond may be formed [46].

\subsubsection{Analysis of XPS spectra}

The surface of ZIF-8 nanoparticles was investigated by XPS to determinate their chemical states in order to better understand the adsorption mechanism. As seen in Fig. 10, the XPS spectra of virgin ZIF-8 nanoparticles indicate that $\mathrm{Zn}, \mathrm{C}$ and $\mathrm{N}$ are main elements present in the sorbent. However, new As 3d core level peak as well as As LMM and As 3p peaks appear in the spectra of ZIF8 nanoparticles after $\mathrm{As}(\mathrm{III})$ or $\mathrm{As}(\mathrm{V})$ adsorption, indicating clearly the presence of arsenic on the surface of the sorbent.

Fig. 11a illustrates the $\mathrm{Zn} 2 \mathrm{p}$ spectra of ZIF-8 nanoparticles before and after arsenic adsorption, and the binding energies of $1021.5 \mathrm{eV}$ and $1044.4 \mathrm{eV}$ for $\mathrm{Zn} 2 \mathrm{p}$ in the spectrum can be attributed to Zn 2p3/2 and Zn 2p1/2, respectively [47]. After loaded with As(III) or $\mathrm{As}(\mathrm{V})$, the peak for $\mathrm{Zn} 2 \mathrm{p}$ shifted slightly to higher binding energy, implying that the $\mathrm{Zn}$ were involved in arsenic sorption [48]. The $\mathrm{N}$ 1s spectra of ZIF-8 nanoparticles before and after arsenic adsorption are compared in Fig. 11b. The binding energy at 398.5, 399.1 eV are attributed to the $\mathrm{N}$ in the $\mathrm{C}=\mathrm{N}-$ and $\mathrm{C}-\mathrm{NH}-$ group, respectively [49]. After arsenic adsorbs on the ZIF-8 nanoparticles, a new peak at $400.6 \mathrm{eV}$ appear, which is attributed to the protonated nitrogen atom coordinate with arsenic. The 0 1s spectra are shown in Fig. 11c. The peaks with binding energy of 531.4 and $532.5 \mathrm{eV}$ are assigned to the $\mathrm{O}$ in the forms of $\mathrm{Zn}-\mathrm{OH}$ and $\mathrm{H}_{2} \mathrm{O}$, respectively [50]. Compared with the spectra of virgin ZIF-8, two new component peaks with binding energy of 530.8 and $531.8 \mathrm{eV}$ are identified after adsorption of arsenic, which are possibly assigned to $\mathrm{Zn}-\mathrm{O}-\mathrm{As}$ and $\mathrm{N}-\mathrm{O}-\mathrm{As}$, respectively $[51,52]$. The As 3d peaks of the ZIF-8 nanoparticles before and after arsenic adsorption are shown in Fig. 11d. The As 3d binding energies at $44.3 \mathrm{eV}$ and $45.4 \mathrm{eV}$ are ascribed to $\mathrm{As}(\mathrm{V})$ and $\mathrm{As}(\mathrm{III})$, respectively [18]. Clearly, no $\mathrm{As}(\mathrm{III})$ was oxidized into $\mathrm{As}(\mathrm{V})$ during the sorption process.

Based on FT-IR and XPS analysis, it can be confirmed that the surface zinc hydroxyl, secondary amine and tertiary amine groups on ZIF-8 nanoparticles serve as active sites for arsenic sorption. The possible sorption mechanisms are illustrated in Fig. 12. Water molecules are adsorbed on ZIF-8 nanoparticles in aqueous solution at $\mathrm{pH}=7.0$, which generates activated sites such as $\mathrm{Zn}-\mathrm{OH}$ and the protonated $\mathrm{N}$ atoms (e.g. $\mathrm{C}=\mathrm{NH}^{+}-, \mathrm{C}-\mathrm{NH}_{2}{ }^{+}-$) groups, through protonated reaction [42]. These positive sites on the ZIF-8 nanoparticles can adsorb the negative arsenate species efficiently via electrostatic attraction. Consequently, the complexes between arsenic species and activated groups can be shown in Fig. 12b.

\subsection{Effect of co-existing anions on arsenic sorption}

The inhibition effect of other anions is an important factor in evaluating applicability of ZIF-8 particles in arsenic adsorption. Most anions such as sulfate, carbonate, phosphate and nitrate, are commonly found in the hydrosphere, which may compete with arsenic for the adsorptive sites on the surface of the sorbents. Therefore, the effects of these anions on $\mathrm{As}$ (III) and $\mathrm{As}(\mathrm{V})$ removal at three concentration levels $(0,2.7$, and $27 \mathrm{mM})$ were examined, and the results are illustrated in Fig. 13. The presence of $\mathrm{SO}_{4}{ }^{2-}$ and $\mathrm{NO}_{3}{ }^{-}$ have no significant effect on the adsorption of both $\mathrm{As}(\mathrm{III})$ and $\mathrm{As}(\mathrm{V})$ even when the concentrations of the anions are almost 100 times higher than that of arsenic. However, the uptake of arsenic on ZIF8 nanoparticles is significantly hindered by the presence of $\mathrm{PO}_{4}{ }^{3-}$ and $\mathrm{CO}_{3}{ }^{2-}$. The obvious inhibition on arsenic adsorption by $\mathrm{PO}_{4}{ }^{3-}$ may be due to the similar adsorption behavior between arsenic and phosphate [53]. Previous studies have indicated that carbonate ions can be adsorbed with zinc as $\equiv \mathrm{Zn}-\mathrm{O}-\mathrm{C}(\mathrm{O})^{-}$, which means that they compete with arsenic for the adsorption sites on the surface of ZIF-8 nanoparticles [54,55].

\section{Conclusions}

In summary, the ZIF-8 nanoparticles, a highly porous material, were successfully synthesized via a facile method at room temperature. The synthesized ZIF-8 nanaoparticles were $200-400 \mathrm{~nm}$ and showed a hierarchical structure with a high surface area of $1063.5 \mathrm{~m}^{2} / \mathrm{g}$. The $\mathrm{pH}_{\text {IEP }}$ of ZIF-8 nanoparticles was around 9.6 and were stable at neutral and basic conditions. However, they dissolved into water at acidic conditions, which dramatically hindered the adsorption of arsenic. The kinetic and isotherm data were well fitted by pseudo-second-order and Langmuir models, respectively. The adsorption isotherm showed that the maximal adsorption capacities of $\mathrm{As}(\mathrm{III})$ and $\mathrm{As}(\mathrm{V})$ on ZIF-8 nanoparticles were of 49.49 
and $60.03 \mathrm{mg} / \mathrm{g}$, respectively, at $T=25^{\circ} \mathrm{C}$ and $\mathrm{pH}$ 7.0. Co-existing anions, $\mathrm{SO}_{4}{ }^{2-}$ and $\mathrm{NO}_{3}{ }^{-}$, had no significant effect on the arsenic adsorption. By contrast, the adsorption was affected significantly by $\mathrm{PO}_{4}{ }^{3-}$ and $\mathrm{CO}_{3}{ }^{2-}$. XPS and FT-IR analysis showed that the adsorption processes may involve the electrostatic attraction and formation of arsenic complexes with hydroxyl and amine groups on the adsorbent.

\section{Acknowledgement}

The authors would like to acknowledge the Joint Research Fund for Overseas Chinese Scholars and Scholars in Hong Kong and Macao (51328803) awarded by the National Natural Science Foundation of China.

\section{Appendix A. Supplementary data}

Supplementary material related to this article can be found, in the online version, at http://dx.doi.org/10.1016/j.colsurfa. 2014.10.023.

\section{References}

[1] B. Manna, U.C. Ghosh, Adsorption of arsenic from aqueous solution on synthetic hydrous stannic oxide, J. Hazard. Mater. 144 (2007) 522-531.

[2] D. Mohan, C.U. Pittman, Arsenic removal from water/wastewater using adsorbents - a critical review, J. Hazard. Mater. 142 (2007) 1-53.

[3] T.S.Y. Choong, T.G. Chuah, Y. Robiah, F.L. Gregory Koay, I. Azni, Arsenic toxicity, health hazards and removal techniques from water: an overview, Desalination 217 (2007) 139-166.

[4] Z. Veličković, G.D. Vuković, A.D. Marinkovic, M.-S. Moldovan, A.A. Perić-Grujić, P.S. Uskoković, M.Đ. Ristic, Adsorption of arsenate on iron(III) oxide coated ethylenediamine functionalized multiwall carbon nanotubes, Chem. Eng. J. 181 (2012) 174-181

[5] J.R. Li, J. Sculley, H.C. Zhou, Metal-organic frameworks for separations, Chem. Rev. 112 (2012) 869-932.

[6] H.-C. Zhou, J.R. Long, O.M. Yaghi, Introduction to metal-organic frameworks, Chem. Rev. 112 (2012) 673-674.

[7] K.S. Park, Z. Ni, A.P. Côté, J.Y. Choi, R. Huang, F.J. Uribe-Romo, H.K. Chae, M. O'Keeffe, O.M. Yaghi, Exceptional chemical and thermal stability of zeolitic imidazolate frameworks, Proc. Natl. Acad. Sci. U.S.A. 103 (2006) 10186-10191.

[8] S.K. Nune, P.K. Thallapally, A. Dohnalkova, C. Wang, J. Liu, G.J. Exarhos, Synthesis and properties of nano zeolitic imidazolate frameworks, Chem. Commun. 46 (2010) 4878-4880.

[9] Z.W. Wu H, T. Yildirim, Hydrogen storage in a prototypical zeolitic imidazolate framework-8, J. Am. Chem. Soc. 129 (2007) 5314-5315.

[10] H. Bux, F. Liang, Y. Li, J. Cravillon, M. Wiebcke, J. Caro, Zeolitic imidazolate framework membrane with molecular sieving properties by microwave-assisted solvothermal synthesis, J. Am. Chem. Soc. 131 (2009) 16000-16001.

[11] G. Lu, J.T. Hupp, Metal-organic frameworks as sensors: a ZIF-8 based FabryPérot device as a selective sensor for chemical vapors and gases, J. Am. Chem. Soc. 132 (2010) 7832-7833.

[12] T.T. Isimjan, H. Kazemian, S. Rohani, A.K. Ray, Photocatalytic activities of Pt/ZIF-8 loaded highly ordered $\mathrm{TiO}_{2}$ nanotubes, J. Mater. Chem. 20 (2010) $10241-10245$

[13] H.B. Loreen Hertäg, J. Caro, C. Chmelik, T. Remsungnen, M. Knauth, S. Fritzsche, Diffusion of $\mathrm{CH}_{4}$ and $\mathrm{H}_{2}$ in ZIF-8, J. Membr. Sci. 377 (2011) 36-41.

[14] J. Yao, D. Dong, D. Li, L. He, G. Xu, H. Wang, Contra-diffusion synthesis of ZIF-8 films on a polymer substrate, Chem. Commun. 47 (2011) 2559-2561.

[15] Y. Pan, Y. Liu, G. Zeng, L. Zhao, Z. Lai, Rapid synthesis of zeolitic imidazolate framework-8 (ZIF-8) nanocrystals in an aqueous system, Chem. Commun. 47 (2011) 2071-2073.

[16] A.F. Gross, E. Sherman, J.J. Vajo, Aqueous room temperature synthesis of cobalt and zinc sodalite zeolitic imidizolate frameworks, Dalton Trans. 41 (2012) 5458-5460.

[17] R.A. Pierotti, J. Rouquerol, Reporting physisorption data for gas/solid systems with special reference to the determination of surface area and porosity, Pure Appl. Chem. 57 (1985) 603-619.

[18] G. Zhang, Z. Ren, X. Zhang, J. Chen, Nanostructured iron(III)-copper(II) binary oxide: a novel adsorbent for enhanced arsenic removal from aqueous solutions, Water Res. 47 (2013) 4022.

[19] K.J.R. Carol, A. Martinson, Adsorption of $\operatorname{arsenic(III)}$ and $\operatorname{arsenic}(\mathrm{V})$ by cupric oxide nanoparticles, J. Colloid Interface Sci. 336 (2009) 406-411.

[20] K.V. Kumar, K. Porkodi, Mass transfer, kinetics and equilibrium studies for the biosorption of methylene blue using Paspalum notatum, J. Hazard. Mater. 146 (2007) 214-226.
[21] K. Gupta, U.C. Ghosh, Arsenic removal using hydrous nanostructure iron(III)titanium(IV) binary mixed oxide from aqueous solution, J. Hazard. Mater. 161 (2009) 884-892.

[22] W.H. Cheung, Y.S. Szeto, G. McKay, Intraparticle diffusion processes during acid dye adsorption onto chitosan, Bioresour. Technol. 98 (2007) 2897-2904.

[23] Y. Su, H. Cui, Q. Li, S. Gao, J.K. Shang, Strong adsorption of phosphate by amorphous zirconium oxide nanoparticles, Water Res. 47 (2013) 5018-5026.

[24] Z. Wang, S.-W. Lee, J.G. Catalano, J.S. Lezama-Pacheco, J.R. Bargar, B.M. Tebo, D.E. Giammar, Adsorption of uranium(VI) to manganese oxides: X-ray absorption spectroscopy and surface complexation modeling, Environ. Sci. Technol. 47 (2013) 850-858.

[25] I. Langmuir, The constitution and fundamental properties of solids and liquids. Part I. Solids, J. Am. Chem. Soc. 38 (1916) 2221-2295.

[26] H. Freundlich, Over the adsorption in solution, J. Phys. Chem. 57 (1906) 385-470.

[27] J.A. Pedit, C.T. Miller, Heterogeneous sorption processes in subsurface systems. 1. Model formulations and applications, Environ. Sci. Technol. 28 (1994) 2094-2104.

[28] A. Gupta, V.S. Chauhan, N. Sankararamakrishnan, Preparation and evaluation of iron-chitosan composites for removal of $\mathrm{As}(\mathrm{III})$ and $\mathrm{As}(\mathrm{V})$ from arsenic contaminated real life groundwater, Water Res. 43 (2009) 3862-3870.

[29] C.S. Jeon, K. Baek, J.K. Park, Y.K. Oh, S.D. Lee, Adsorption characteristics of As(V) on iron-coated zeolite, J. Hazard. Mater. 163 (2009) 804-808.

[30] S.M. Maliyekkal, L. Philip, T. Pradeep, As(III) removal from drinking water using manganese oxide-coated-alumina: performance evaluation and mechanistic details of surface binding, Chem. Eng. J. 153 (2009) 101-107.

[31] K. Gupta, T. Basu, U.C. Ghosh, Sorption characteristics of arsenic(V) for removal from water using agglomerated nanostructure iron(III)-zirconium(IV) bimetal mixed oxide, J. Chem. Eng. Data 54 (2009) 2222-2228.

[32] G.-S. Zhang, J.-H. Qu, H.-J. Liu, R.-P. Liu, G.-T. Li, Removal mechanism of As(III) by a novel Fe-Mn binary oxide adsorbent: oxidation and sorption, Environ. Sci. Technol. 41 (2007) 4613-4619.

[33] J.K.B. Abhijit Maiti, Sirshendu De, Experimental and kinetic modeling of As(V) and $\mathrm{As}(\mathrm{III})$ adsorption on treated laterite using synthetic and contaminated groundwater, Chem. Eng. J. 191 (2012) 1-12.

[34] Q.L. Cui Hang, S. Gao, J.K. Shang, As(III) and As(V) adsorption by hydrous zirconium oxide nanoparticles synthesized by a hydrothermal process followed with heat treatment, Ind. Eng. Chem. Res. 51 (2012) 353-361.

[35] N.B. Steven Luther, J. Kim, J.G. Parsons, Removal of arsenic from aqueous solution: a study of the effects of $\mathrm{pH}$ and interfering ions using iron oxide nanomaterials, Microchem. J. 101 (2012) 30-36.

[36] Z. Ren, G. Zhang, J.P. Chen, Adsorptive removal of arsenic from water by an iron-zirconium binary oxide adsorbent, J. Colloid Interface Sci. 358 (2011) 230-237.

[37] G. Li, J. Lan, J. Liu, G. Jiang, Synergistic adsorption of As(V) from aqueous solution onto mesoporous silica decorated orderly with $\mathrm{Al}_{2} \mathrm{O}_{3}$ and $\mathrm{Fe}_{2} \mathrm{O}_{3}$ nanoparticles, J. Colloid Interface Sci. 405 (2013) 164-170.

[38] L.H. Dubois, R.G. Nuzzo, Synthesis, structure, and properties of model organic surfaces, Annu. Rev. Phys. Chem. 43 (1992) 437-463.

[39] Y. Shen, Y. Zhang, Q. Zhang, L. Niu, T. You, A. Ivaska, Immobilization of ionic liquid with polyelectrolyte as carrier, Chem. Commun. (2005) 4193-4195.

[40] Y. Hu, H. Kazemian, S. Rohani, Y. Huang, Y. Song, In situ high pressure study of ZIF-8 by FTIR spectroscopy, Chem. Commun. 47 (2011) 12694-12696.

[41] M. He, J. Yao, Q. Liu, K. Wang, F. Chen, H. Wang, Facile synthesis of zeolitic imidazolate framework-8 from a concentrated aqueous solution, Microporous Mesoporous Mater. 184 (2014) 55-60.

[42] C. Chizallet, S. Lazare, D. Bazer-Bachi, F. Bonnier, V. Lecocq, E. Soyer, A.-A. Quoineaud, N. Bats, Catalysis of transesterification by a nonfunctionalized metal-organic framework: acido-basicity at the external surface of ZIF-8 probed by FTIR and ab initio calculations, J. Am. Chem. Soc. 132 (2010) $12365-12377$

[43] M. Pena, X. Meng, C. Jing, Adsorption mechanism of arsenic on nanocrystalline titanium dioxide, Environ. Sci. Technol. 40 (2006) 1257-1262.

[44] P. Castaldi, M. Silvetti, S. Enzo, P. Melis, Study of sorption processes and FT-IR analysis of arsenate sorbed onto red muds (a bauxite ore processing waste), J. Hazard. Mater. 175 (2010) 172-178.

[45] S. Goldberg, C.T. Johnston, Mechanisms of arsenic adsorption on amorphous oxides evaluated using macroscopic measurements, vibrational spectroscopy, and surface complexation modeling, J. Colloid Interface Sci. 234 (2001) 204-216.

[46] C.H. Rochester, G.H. Yong, Infrared study of the adsorption of amines on silica immersed in carbon tetrachloride, J. Chem. Soc, Faraday Trans. 176 (1980) $1158-1165$.

[47] R. Dom, R. Subasri, N.Y. Hebalkar, A.S. Chary, P.H. Borse, Synthesis of a hydrogen producing nanocrystalline $\mathrm{ZnFe}_{2} \mathrm{O}_{4}$ visible light photocatalyst using a rapid microwave irradiation method, RSC Adv. 2 (2012) 12782-12791.

[48] Z. Li, S. Deng, G. Yu, J. Huang, V. Chao, As(V) and As(III) removal from water by a Ce-Ti oxide adsorbent: behavior and mechanism, Chem. Eng. J. 161 (2010) 106-113.

[49] S. Deng, G. Yu, S. Xie, O. Yu, J. Huang, Y. Kuwaki, M. Iseki, Enhanced adsorption of arsenate on the aminated fibers: sorption behavior and uptake mechanism, Langmuir 24 (2008) 10961-10967.

[50] R. Wahab, S.G. Ansari, Y.S. Kim, H.K. Seo, G.S. Kim, G. Khang, H.-S. Shin, Low temperature solution synthesis and characterization of $\mathrm{ZnO}$ nano-flowers, Mater. Res. Bull. 42 (2007) 1640-1648. 
[51] J. Yu, X. Yu, Hydrothermal synthesis and photocatalytic activity of zinc oxide hollow spheres, Environ. Sci. Technol. 42 (2008) 4902-4907.

[52] C. Egawa, S. Naito, K. Tamaru, Adsorption and decomposition of $\mathrm{NO}$ and $\mathrm{NH}_{3}$ on $\mathrm{Ru}(001)$ and Ru $(1,1,10)$ surfaces, Surf. Sci. 138 (1984) 279-291.

[53] A. Jain, R. Loeppert, Effect of competing anions on the adsorption of arsenate and arsenite by ferrihydrite, J. Environ. Qual. 29 (2000) 1422-1430.
[54] I. Carabante, M. Grahn, A. Holmgren, J. Kumpiene, J. Hedlund, Influence of Zn(II) on the adsorption of arsenate onto ferrihydrite, Environ. Sci. Technol. 46 (2012) $13152-13159$

[55] G. Lefèvre, In situ Fourier-transform infrared spectroscopy studies of inorganic ions adsorption on metal oxides and hydroxides, Adv. Colloid Interface Sci. 107 (2004) 109-123. 